\title{
Notes on the vocalizations of Olive Bulbul (Iole virescens)
}

Peter Boesman

In the following we briefly analyze and compare voice of the three races of Olive Bulbul (Iole virescens). We also try to quantify the extent of any vocal differences using the criteria proposed by Tobias et al. (2010), as a support for taxonomic review. We have made use of sound recordings available on-line from Xeno Canto (XC).

There are very few recordings available. An overview per race:

virescens
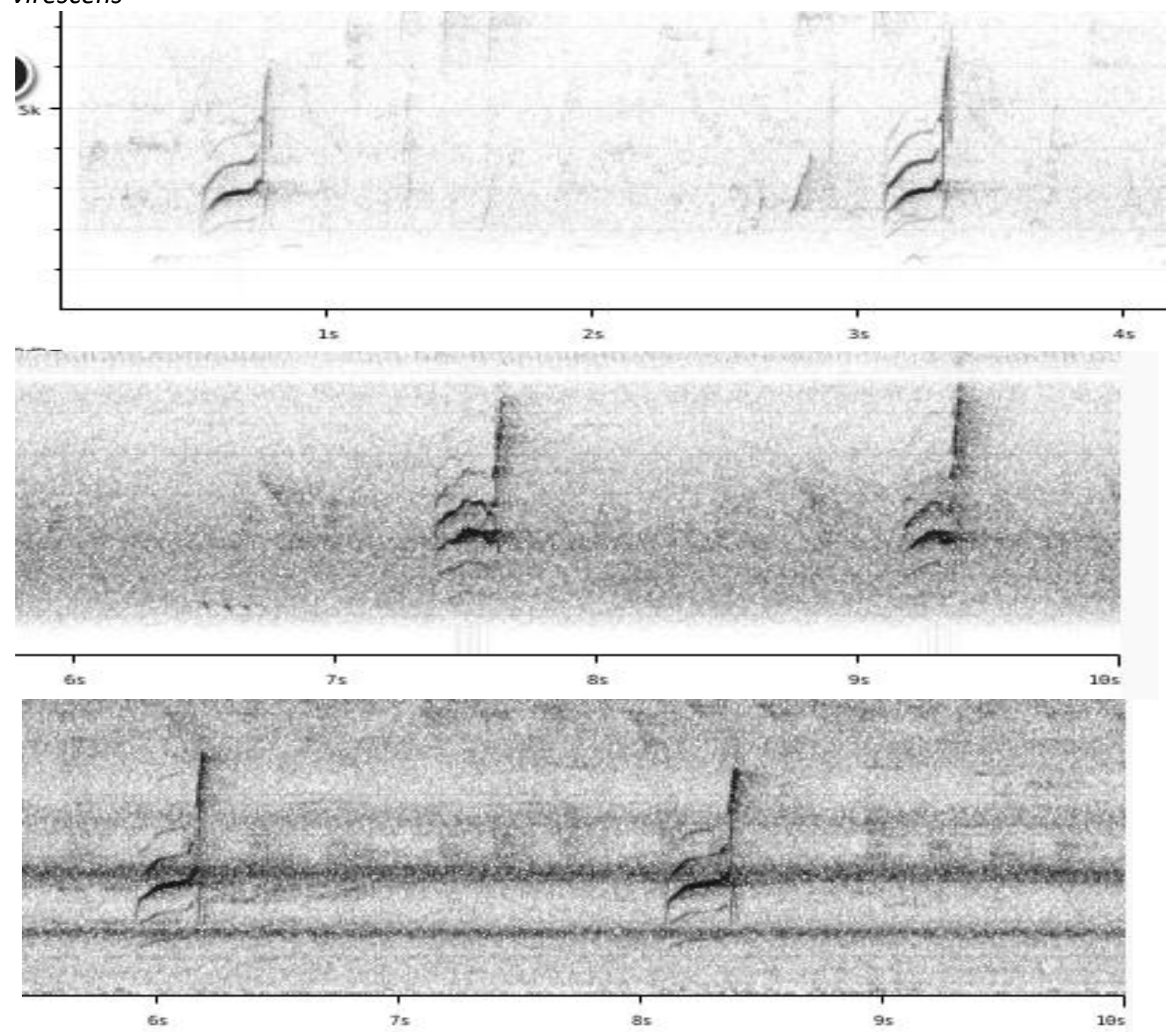


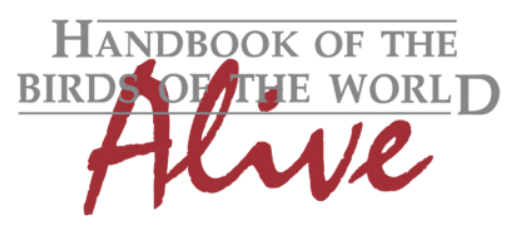

\section{ORNITHOLOGICAL NOTES}
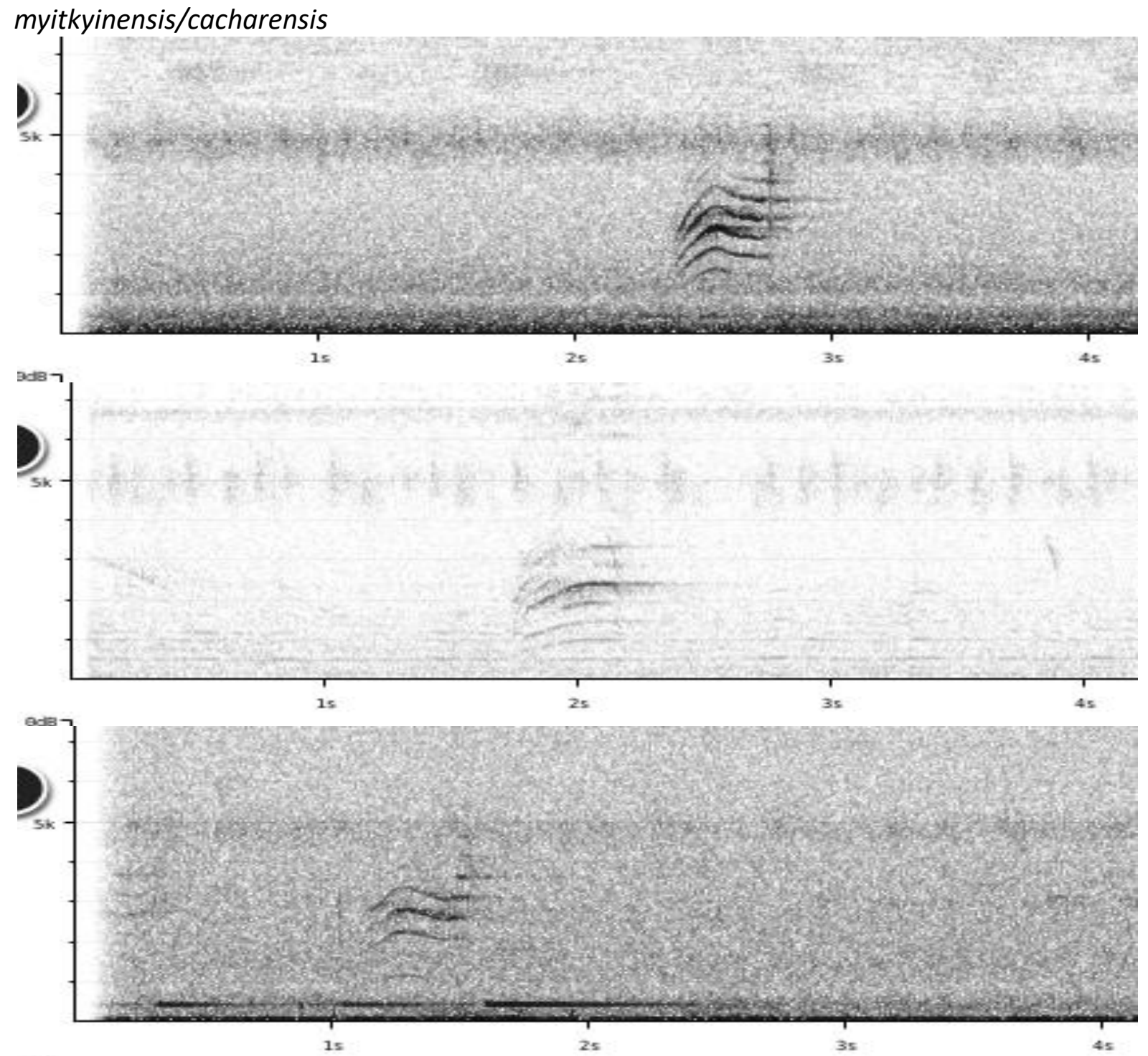

Presumed song of both groups is structurally similar, but differences are clearly audible to the ear: virescens is slightly higher-pitched and with clear upward inflection at the end. myitkyinensis/cacharensis is more drawn-out and rather falling in pitch towards the end.

Given that voice in the genus is not very diverse, this is quite significant, e.g. a selected recording from $O$. olivacea is close to virescens but higher-pitched

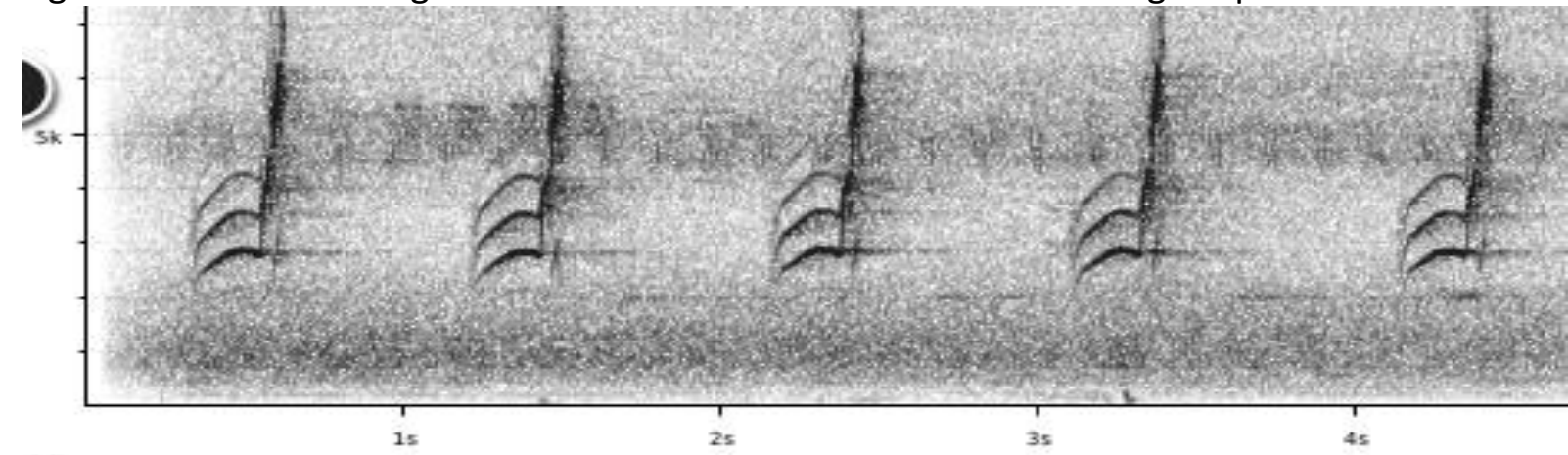



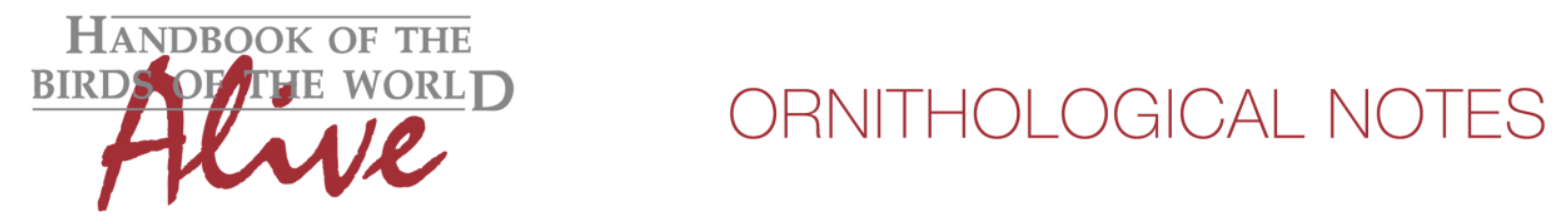

and a selected recording of $O$. propinqua is also rather similar:

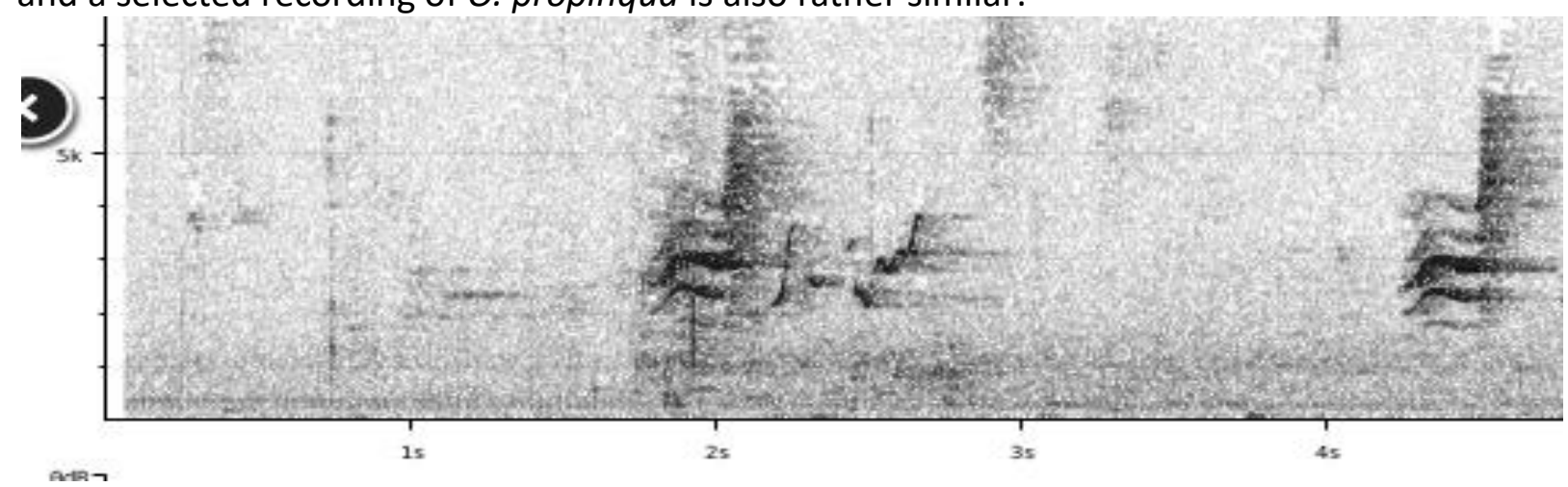

As vocal differentiation in this genus is apparently quite limited, the group myitkyinensis/cacharensis clearly stands apart.

A vocal score could be given as voice of virescens is slightly higher-pitched (score 1-2) and with clear upward inflection at the end (score 2-3, quantifiable as freq. start - freq. end), while voice of myitkyinensis/cacharensis is more drawn-out (score 2) and rather falling in pitch towards the end. When applying Tobias criteria, this would lead to a total vocal score of about 4 , with the important remark however that more recordings are needed to confirm these vocal differences.

This note was finalized on 19th February 2016, using sound recordings available on-line at that moment. We would like to thank in particular the sound recordists who placed their recordings for this species on XC: Ross Gallardy, Greg Irving, Vijay Anand Ismavel and Martjan Lammertink.

\section{References}

Tobias, J.A., Seddon, N., Spottiswoode, C.N., Pilgrim, J.D., Fishpool, L.D.C. \& Collar, N.J. (2010). Quantitative criteria for species delimitation. Ibis 152(4): 724-746.

\section{Recommended citation}

Boesman, P. (2016). Notes on the vocalizations of Olive Bulbul (Iole virescens). HBW Alive Ornithological Note 242. In: Handbook of the Birds of the World Alive. Lynx Edicions, Barcelona. (retrieved from http://www.hbw.com/node/932239 on 30 September 2016). 